\title{
Sistem Informasi Catholic Center Medan Berbasis Web
}

\author{
1) Mei Yanti Panjaitan \\ UNIKA Santo Thomas Sumatera Utara, JI Setiabudi No. 479 F Tanjungsari Medan \\ http://www.ust.ac.id // Email : Meiyanti223@gmail.com \\ ${ }^{2)}$ Romanus Damanik \\ UNIKA Santo Thomas Sumatera Utara, JI Setiabudi No. 479 F Tanjungsari Medan \\ http://www.ust.ac.id // Email : rayhandamanik@gmail.com
}

\begin{abstract}
At present, many people use technology as a material to simplify work, the technology used is technology based online and offline. Nowadays technology is also used as a medium for the wider community to get information and communicate with each other wherever and whenever. Catholic Center "Christosophia" Medan Archdiocese, is engaged in an integrated service center that aims to improve services for all Catholics and other religious institutions. Catholic Center Archdiocese of Medan also provides various places such as: meeting room, lodging, hall and prayer room data. The resulting web display can provide convenience in terms of leasing in a web-based terrain catholic center, the advantage of this system is that there is a member and non-member system that is to improve the quality of building leases made by customers, and if the customer is a member then the customer can get discounted place price with the stipulated conditions. And with the system of members and non-members, it will make customers satisfied with the service and excellence available at the Catholic Center, and can help leaders maintain their customers and find new customers.
\end{abstract}

Kata kunci : pelanggan, penyewaan gedung, Web, Sistem Informasi

\section{PENDAHULUAN}

Saat ini perkembangan semakin pesat dan teknologi mendorong semua pihak untuk tanggap terhadap situasi dan kondisi yang ada. Persaingan di dunia bisnis juga semakin tinggi khususnya dalam hal penyewaan gedung. Menghadapi persaingan yang tinggi itu perlu dilakukan strategi agar permasalahan permasalahan yang ada dapat diatasi dengan baik. Adapun hal-hal yang melatarbelakangi permasalahan tersebut meliputi permasalahan dalam pengolahan data meeting room, penginapan, hall dan khususnya di Catholic Center Medan.

Komputer saat ini merupakan kebutuhan manusia di dalam melakukan berbagai kegiatan, ditambah dengan adanya teknologi informasi yang semakin berperan didalam dunia kerja ataupun dunia bisnis. Dengan menggunakan piranti teknologi informasi yang tepat, maka akan dihasilkan informasi yang tepat dan akurat sesuai dengan kebutuhan sehingga keputusan dapat diambil dengan cepat, ada pun hal yang masih dilakukan di Catholic Center selama ini pelanggan jika ingin mendapatkan informasi atau memesan tempat, harus datang ke bagian informasi dan bertanya langsung dengan pihak yang mengolah bagian tersebut sehingga terkadang informasi yang dihasikan hanya berupa pendataaan yang manual dan kurang efektif $^{[7]}$.

Catholic Center "Christosophia" Keuskupan Agung Medan, bergerak dibidang pusat pelayanan terpadu yang bertujuan untuk meningkatkan pelayanan bagi seluruh umat dan lembaga katolik maupun lembaga keagamaan lainnya. Gedung Catholic Center Keuskupan Agung Medan juga menyediakan berbagai tempat seperti: meeting room, penginapan, dan hall, pengolahan data penyewaan gedung akan semakin efektif jika menggunakan komputer sebagai alat bantu, oleh sebab itu diperlukan sebuah sistem informasi yang dapat mengolah data yang berhubungan dengan pengolahan data penyewaan gedung seperti, meeting room, penginapan, dan hall. karena sistem Catholic Center sebelumnya belum memiliki sistem, sehingga sering terjadi kesalahan dalam pengolahan data, untuk itu diperlukan suatu aplikasi yang dapat membantu menginformasikan tentang ketersediaan meeting room, penginapan, dan hall agar mempercepat proses pengolahan data penyewaan gedung pada Catholic Center dan meningkatkan kepuasan pelanggan ${ }^{[5]}$.

Berdasarkan uraian diatas maka penulis tertarik dan mencoba membuat suatu sistem untuk pengolahan data 
penyewaan gedung meeting room penginapan dan hall, khususnya di Catholic Center Medan dengan judul "Sistem Informasi Catholic Center Medan Berbasis Web".

Adapun rumusan masalah berdasarkan uraian latar belakang di atas adalah sebagai berikut: 1) Bagaimana sistem pelayanan admin kepada pelanggan di Catholic center dalam hal pemesanan gedung ? ; 2) Bagaimana pelanggan mencari lokasi Catholic center ? ; 3) Bagaimana cara mengatasi permasalahan pemesanan gedung di Catholic center selama ini ?

Untuk mengatasi agar pembahasan tidak menyimpang dari maksud dan tujuan utama tulisan, maka diberikan batasan masalah sebagai berikut: Sistem ini mendata :

meeting room, penginapan dan hall, Membahas pengolahan data penyewaan gedung, Data member/non member.

Adapun manfaat dari penelitian ini adalah Memberikan informasi tentang pengolahan data penyewaan gedung yang lengkap dan efektif, mempermudah orang dalam pemesanan dan tidak menghabiskan waktu banyak, sistem menjadi online ke internet.

\section{LANDASAN TEORI}

\subsection{Sistem}

Sistem adalah sekumpulan elemen yang saling terkait atau terpadu yang dimaksudkan untuk mencapai suatu tujuan. Sebagai gambaran, jika dalam sebuah sistem terdapat elemen yang tidak memberikan manfaat, maka elemen tersebut dapat dipastikan bukanlah elemen dari suatu sistem $^{[4]}$.

\subsection{Elemen Sistem}

Elemen - elemen yang membentuk sebuah sistem yaitu : Setiap sistem memiliki Tujuan (goal), entah hanya satu atau mungkin banyak. Tujuan inilah yang menjadi pemotivasi yang mengarahkan sistem. Tanpa tujuan, sistem menjadi tidak terarah dan tidak menjadi terkendali. Tentu saja tujuan antara satu sistem dengan sistem lain berbedabeda. Begitu pula yang berlaku pada sistem informasi. Setiap sistem informasi memiliki suatu tujuan, tetapi dengan tujuan yang berbeda-beda. Walaupun begitu, tujuan utama yang umum ada tiga macam (Hall, 2001), yaitu:
1. Untuk
mendukung
kepengurusan manajemen,
2. Untuk mendukung pengambilan keputusan manajemen,

3. Untuk mendukung kegiatan operasi perusahaan.

\subsection{Konsep Dasar Penyewaan}

Pengertian sewa menurut kamus besar bahasa Indonesia (departemen pendidikan dan kebudayaan republik Indonesia 2001) adalah pemakaian sesuatu dengan membayar uang sewa, uang yang dibayarkan karena memakai atau meminjamkan sesuatu, yang boleh pakai dengan membayar uang dengan uang. Sedangkan pengertian penyewaan adalah proses, cara, pembuatan menyewa atau menyewakan. Yang dimaksud dengan sewa, yaitu balas jasa atas sewa ruangan dalam keadaan kosong yang dapat ditagih dimuka (pada awal penyewaan) atau dibelakang, sesuai dengan kontrak/ perjanjian.

\subsection{Konsep Dasar Informasi}

Informasi merupakan salah satu sumber daya penting dalam manajemen modern. Banyak keputusan strategis yang bergantung kepada informasi. Menurut Ebert dan Grifin (2003) dalam (Kadir, 2013) Manajemen informasi ialah sebagai operasi-operasi internal yang mengatur sumber daya informasi dalam perusahaan untuk mendukung kinerja dan hasil bisnis.

\subsection{Data}

Dalam membentuk suatu sistem informasi, diperlukan komponen masukan berupa datadata yang diperlukan sebagai bahan mentah sistem tersebut. Menurut Kadir data adalah deskripsi tentang benda, kejadian, aktivitas, dan transaksi yang tidak mempunyai makna atau tidak berpengaruh secara langsung kepada pemakai. Data sering kali disebut sebagai bahan mentah informasi. Melalui suatu proses transformasi, data dibuat menjadi bermakna ${ }^{[4]}$.

\section{METODE DAN PEMBAHASAN}

\subsection{Metodologi Penelitian}
1. Penelitian kepustakaan research)
Studi pustaka adalah pengumpulan data buku yang berkaitan dengan masalah yang sedang dihadapi dalam penelitian.
2. Penelitian Lapangan (Field research) Observasi yaitu penulis melakukan peninjauan secara langsung ke lapangan, untuk mendapat informasi yang dibutuhkan dalam informasi tentang meeting room, penginapan, hall dan ruang doa
3. Metode Wawancara (Interview) 
Teknik pengumpulan data yang dilakukan dengancara tanya jawab langsung dengan petugas yang terkait di dalamnya dalam hal ini karyawan dan manager.

\subsection{Perancangan Sistem}

Perancangan sistem berfungsi untuk mengetahui bentuk dari sistem yang akan dibangun dan apa saja yang akan dibutuhkan dalam membangun sebuah sistem ${ }^{[10]}$. Perancangan Sistem Informasi Catholic Center Medan Berbasis Web ini akan menyajikan banyak fitur seperti data gedung dan jenis gedung, data fasilitas, data ketentuan penyewaan dan ketentuan menjadi member, penyewaan gedung dan konfirmasi uang muka secara online ${ }^{[9]}$.

Setiap pengguna gedung dan pihak management juga dapat berkomunikasi secara online melalui sarana chating. Maka pada dasarnya sistem ini akan mengerjakan pekerjaan tersebut secara otomatis. Pada perancangan sistem ada beberapa tahapan yang harus dilakukan, yaitu sebagai berikut:

\subsection{Diagram Konteks}

Diagram konteks merupakan gambaran keseluruhan dari suatu sistem, yang tujuannya memberikan pandangan secara umum tentang sistem dan memperlihatkan sebuah proses yang berinteraksi dengan lingkungannya. Diagram konteks pada Perancangan Sistem Informasi Catholic Center Medan Berbasis Web dapat dilihat seperti pada Gambar 1.

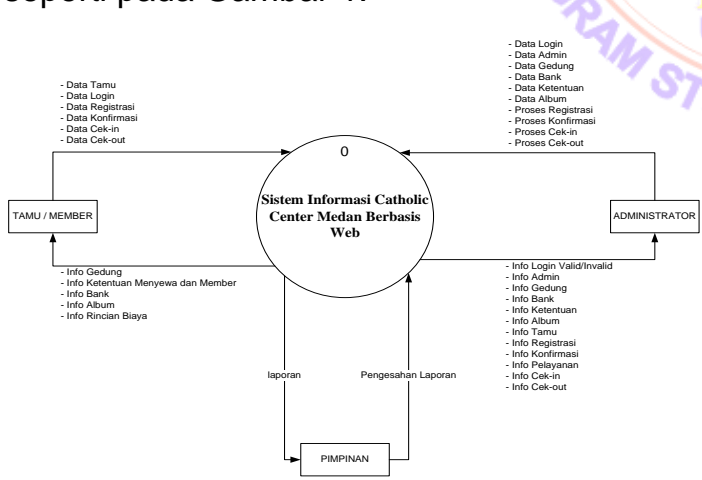

Gambar 1. Diagram Konteks

\section{HASIL DAN IMPLEMENTASI}

\subsection{Implementasi Sistem}

Implementasi sistem adalah tahap penerapan sistem yang akan dilakukan jika sistem disetujui termasuk program yang telah dibuat pada tahap peTampilan sistem agar siap untuk dioperasikan. Bab ini berisi uraian mengenai tahapan untuk membangun/mewujudkan Tampilan sistem baru secara nyata. Sistem Informasi Catholic Center Medan Berbasis Web terdapat beberapa halaman yang dapat diakses oleh masing-masing pengguna yang berbeda. Setiap halaman dan cara penggunaan halaman akan dijelaskan pada tahap ini.

\subsection{Halaman Pengunjung Umum}

Halaman ini merupakan halaman public atau halaman yang dapat diakses setiap pengunjung website Catholic Center. Pada halaman ini setiap pengunjung dapat mengakses informasi tentang Catholic Center adapun halaman yang dapat diakses oleh setiap pengunjung umum adalah:

1. Tampilan Halaman Utama

Halaman utama atau beranda merupakan tampilan utama pada saat sistem atau website dijalankan, dimana pada halaman utama banyak terdapat pilihan link yang berguna untuk berpindah dari satu halaman ke kelaman lainnya. Bentuk halaman utama dapat dilihat pada Gambar 2 ..

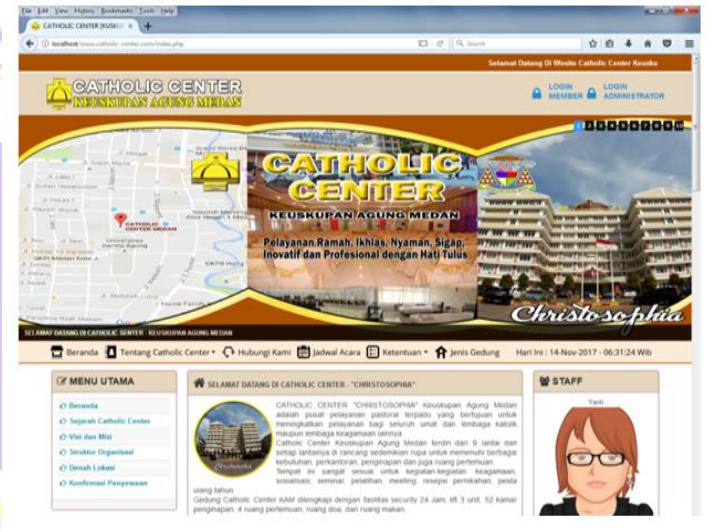

Gambar 2. Tampilan Halaman Utama

2. Tampilan Sejarah Catholic Center Medan

Halaman sejarah Catholic Center Medan akan menyajikan informasi sejarah berdirinya Catholic Center Medan. Bentuk Tampilan halaman sejarah Catholic Center Medan dapat dilihat pada Gambar 3.

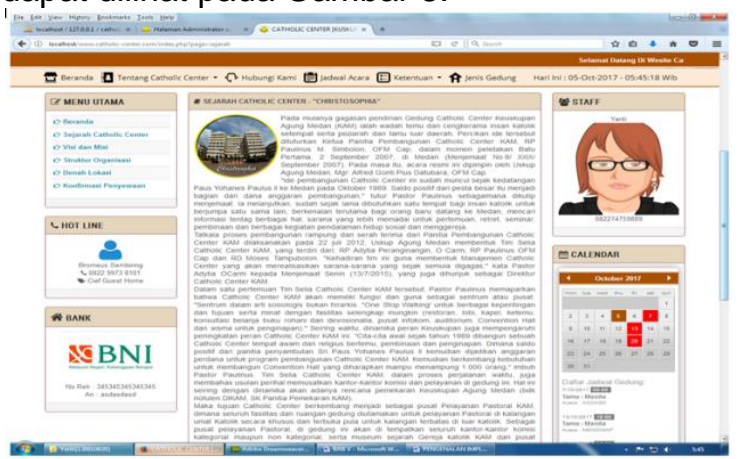

Gambar 3. Tampilan Sejarah Catholic Center Medan 
3. Tampilan Proses Registrasi Pemakaian Gedung

Tampilan proses registrasi pemakaian gedung berfungsi untuk melakukan registrasi pemakaian gedung pada Catholic Center Medan. Bentuk Tampilan input registrasi pemakaian gedung dapat dilihat pada Gambar 4.

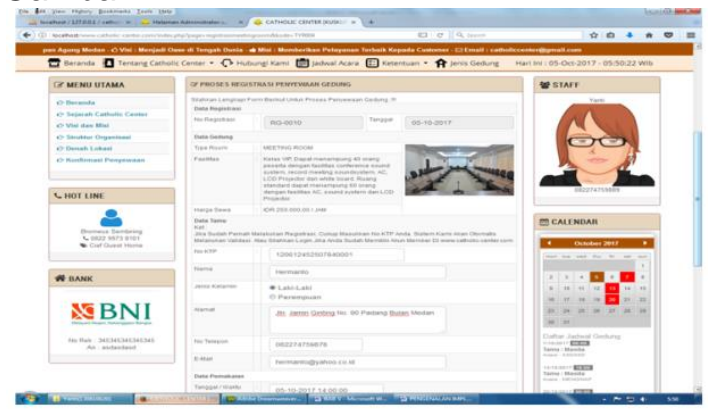

Gambar 4. Tampilan Proses Registrasi Pemakaian Gedung

\section{B. Halaman Member}

Halaman member dapat diakses oleh setiap member yang sudah ditentukan oleh admin untuk masuk kehalaman ini setiap member wajib melakukan login terleih dahulu. Adapun halaman yang dapat diakses oleh setiap member adalah:

Halaman login member berfungsi untuk masuk ke halaman member Catholic Center Medan. Bentuk Tampilan halaman login member dapat dilihat seperti pada Gambar 5.

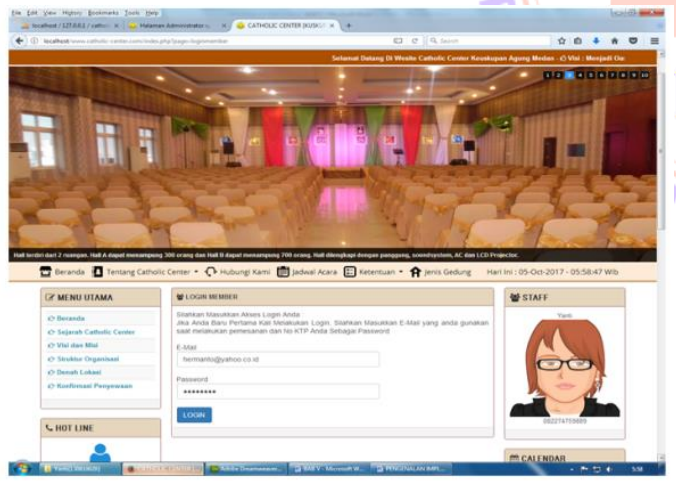

Gambar 5. Tampilan Halaman Login Member

Halaman administrator adalah halaman yang hanya dapat diakses oleh seorang admin di Catholic Center, untuk masuk kehalaman ini seorang admin wajib melakukan login terleih dahulu. Adapun halaman yang dapat diakses oleh seorang admin adalah:

1. Tampilan Halaman Input Login

Administrator

Halaman input login administrator berfungsi untuk masuk ke halaman administrator Catholic Center Medan. Bentuk Tampilan halaman input login administrator dapat dilihat seperti pada Gambar 6 .

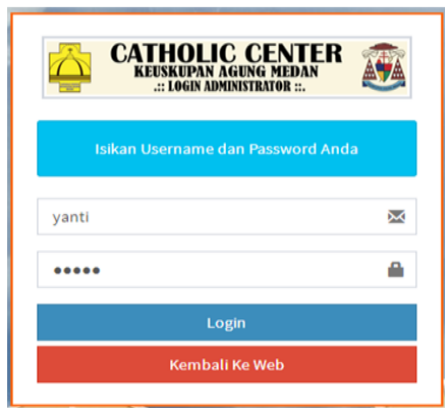

Gambar 6. Tampilan Halaman Input Login Administrator

\section{Output dan Laporan}

Hasil akhir sistem merupakan tujuan utama dalam membangun sebuah sistem. Berikut adalah hasil akhir yang dihasilkan sistem, bentuk pencetakan laporan adalah dalam bentuk Portable Document Format.

1. Hasil Sistem Daftar Gedung

Tampilan daftar gedung berfungsi untuk mencetak daftar gedung atau ruangan yang ada pada Catholic Center. Dimana daftar gedung dapat dibedakan berdasarkan jenis gedung atau pun keseluruhan. Tampilan daftar gedung dapat dilihat seperti pada Gambar 7

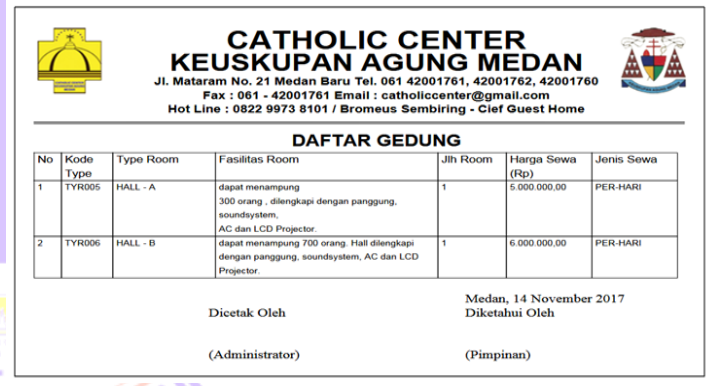

Gambar 7. Hasil Sistem Daftar Gedung

2. Hasil Sistem Bukti Booking Ruangan Hasil Sistem bukti booking ruangan berfungsi sebagai bukti pemesanan ruangan yang dilakukan oleh pengunjung. Tampilan bukti booking ruangan dapat dilihat seperti pada Gambar 8

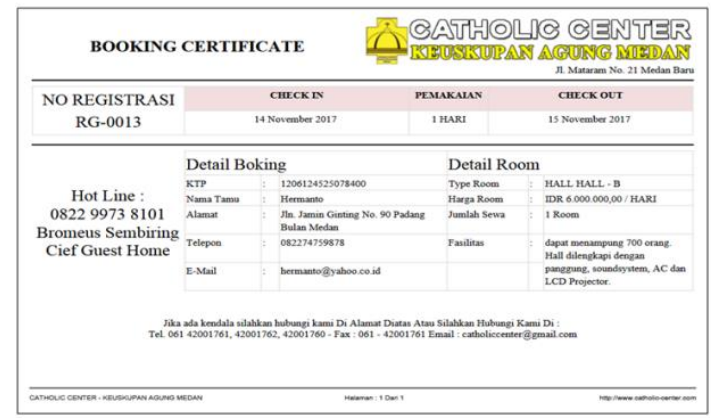

Gambar 8 . Hasil Sistem Bukti Booking Ruangan

KESIMPULAN DAN SARAN

5.1. Kesimpulan 
Dari proses analisis, perancangan yang dilakukan pada bab-bab sebelumnya, maka dapat diambil kesimpulan sebagai berikut:

1. Dengan adanya sistem baru ini, maka proses penyewaan mulai dari proses registrasi, pemesanan tempat, dan pembuatan laporan penyewaan dapat dilakukan dengan baik dan efisien, dan akan menyajikan banyak fitur seperti data gedung dan jenis gedung, data fasilitas, data ketentuan penyewaan dan ketentuan menjadi member, penyewaan gedung dan konfirmasi uang muka secara online. Dan sistem yang dibangun dapat menampilkan secara online melalui sarana chating.

2. Proses pemesanan dan penyewaan dapat dilakukan dengan cepat, dimana member dapat langsung melakukan pemesanan melalui website yang telah dibuat dan pelanggan bebas memesan tanpa harus datang ke lokasi dan bertanya lagi kepada bagian umum

\subsection{Saran}

Adapun saran yang dapat penulis berikan untuk pengembangan dari sistem yang telah dibuat antara lain :

1. Kepada pembaca, penulis menyarankan agar dapat lebih mengembangkan lagi sistem yang penulis rancang ini menjadi sistem yang lebih sempurna lagi dan lebih meluas cakupan ruang lingkup sistem ini.

2. Kepada pengguna sistem informasi penyewaan gedung hendaknya memperhatikan bagaimana sistem informasi ini berjalan dengan baik dalam penggunaannya dan tidak mengalami masalah.

\section{DAFTAR PUSTAKA}

1. Bhirawa Anoraga Nandari Dkk. Citec Journal: Volume 3 No 3 Juli - 2014. Pembuatan Website Portal Berita Desa JetisLor, ISSN: 2302-5700.

2. Della Mochamad Frayoga As Dkk. Rancang Bangun Penyewaan Dan Pengelolaan Data Alat Keping Berbasis Dekstop Pada Perusahaan Perorangan RZ Adventure., Jurnal Algoritma Sekolah Tinggi Teknologi Garut. ISSN: 2302-7339 Vol. 13, No. 12016

3. Fatansyah. 2012. Basis Data Edisi Revisi. Bandung: Informatika.

4. Kadir Abdul. 2013. Pengenalan Sistem Informasi, Yogyakarta: Andi, Edisi Revisi. Majalah Catholic Center, Agustus 2015)
5. Nore Victor Nicolas. "Perancangan Sistem Informasi Penjualan dan Pemesanan Produk Berbasis Web", Jurnal International Association Of Universities, 1:1, 27 - 29 (Bandung, Januari 2013).

6. Rulia Puji Hastanti Dkk. Citec Journal: Vol 3 No 2- September 2015. Sistem Penjualan Berbasis Web (E-Commerce) Pada Tata Distro, ISSN :2338-8145.

7. Ruslan. "Pengelolaan Reservasi Hotel Melalui Aplikasi Berbasis Website, Jurnal Sigmata | LPPM AMIK Sigma, Volume 4 : Nomor : 2 Edisi : April 2016 - September 2016, ISSN 2302-5786.

8. Sibero, Alexander F.K. 2013,. Web Programming Power Pack, Jakarta: MediaKom.

9. Supriyanta Khoirun Nisa "Perancangan Website Desa Wisata Karangrejo Sebagai Media Informasi Dan Promosi", Vol 3 No 1 Maret 2015.

10. Sutabri tata. 2012. Sistem Informasi, Yogyakarata, Andi Offset. 